\title{
TRABAJAR EN TIEMPOS DE PANDEMIA: ¿ANTESALA DE NUESTRO FUTURO LABORAL?
}

Giorgio Boccardo Bosoni 


\section{GIORGIO BOCCARDO BOSONI}

Sociólogo y académico del Departamento de Sociología en la Universidad de Chile. Se ha especializado en temas de trabajo, conflicto y formación de clases sociales durante la era neoliberal. Actualmente se encuentra investigado sobre automatización y conflictos en el proceso de trabajo en Chile. Fue presidente de la Fech en 2006-2007 y es director de la Fundación Nodo XXI. 


\section{TRABAJAR EN TIEMPOS DE PANDEMIA: ¿ANTESALA DE NUESTRO FUTURO LABORAL?}

En los últimos meses, el capitalismo ha entrado en un estado de hibernación cuya duración y alcances son aún difíciles de prever. Los gobiernos han reaccionado con diversas políticas de control sanitario y planes de salvataje para sostener empleos, salarios y la viabilidad de las empresas. Sin embargo, la pandemia mostró con crudeza que tras casi medio siglo de neoliberalismo el mundo no se encuentra suficientemente preparado para proteger la vida de la población. Los Estados cuentan con pocas herramientas institucionales para intervenir la economía, la seguridad social alcanza solo para una fracción de la fuerza de trabajo y una eventual vacuna quedará en manos de gigantes farmacéuticos multinacionales.

Las primeras reflexiones sobre la crisis y un mundo pospandemia han provenido desde la filosofía". El italiano Giorgio Agamben denunció que el "estado de catástrofe" era una invención destinada a fortalecer el carácter autoritario de los Estados y reducir nuestras libertades, en tanto, el coreano Byung-Chul Han señaló que el virus nos dejaría más aislados y carentes de sentimientos colectivos. Con cierto dejo de euforia, el esloveno Slavoj Žižek sentenció que el Coronavirus era un "golpe al corazón del capitalismo" y que abría oportunidades para reinventar el comunismo. No obstante, la elaboración más sugerente fue realizada por la estadounidense Judith Butler, quien sostuvo que la pandemia puso en evidencia los límites del capitalismo y la centralidad del mercado en la vida social, así como la importancia de una salud pública de cobertura universal. En ese sentido, Butler hace una invitación profunda a repensar el papel del Estado y su relación con la sociedad e individuos, al mismo tiempo que ve en la crisis una oportunidad para revitalizar los imaginarios socialistas.

La economía política ha centrado las discusiones en la hondura de la recesión (Roubini, 2020) y en la urgencia de políticas para "salvar al capitalismo" de sus propios demonios (Stiglitz, 2020). El Financial Times, de conocida orientación monetarista, sentenció que "el virus mostró la fragilidad de nuestro contrato social" e interpeló a realizar reformas radicales para fortalecer el papel del Estado en la economía, elevar impuestos a las grandes fortunas para reducir desigualdades y proteger al trabajo de nuevas incertidumbres (The Editorial Board, 2020). Desde

1. Para una revisión detallada de este debate, revisar la compilación realizada por Pablo Amadeo (2020). 
diversas orientaciones ideológicas se propone inaugurar una nueva "era keynesiana" de carácter global, sin embargo, el mundo que habitamos hoy es muy diferente de aquel de la Gran Depresión de 1929. En la actualidad predomina el capital financiero sobre el industrial, gigantes tecnológicos extienden sus redes de poder sobre todo el mundo y la clase obrera industrial carece de fuerza para obligar a nuevos pactos de bienestar.

El dilema de cómo prefigurar un mundo pospandemia no es en lo fundamental una cuestión de orden económico. De hecho, cuando se propone forjar un contrato social hablamos de actores y relaciones de poder que permiten alcanzar un acuerdo duradero. Pero también de modos de organizar nuestra vida colectiva, formas de asegurar nuestras libertades y posibilidades de alcanzar niveles razonables de bienestar. Entonces, uno de los elementos que inmediatamente emerge al pensar en pactos es la fuente que nos provee del sustento diario que, hasta el día de hoy, sigue siendo el trabajo (Antunes y Mészáros, 2005). No obstante, tras décadas de neoliberalismo, la pandemia se ha encargado de recordarnos que los salarios, contratos e instituciones de seguridad social han perdido toda capacidad para entregarnos certezas (Castel, 2010).

El problema no es solo advertir que el trabajo del siglo XX está por desaparecer. La cuestión es distinguir situaciones laborales propias de la crisis sanitaria, que deben ser enfrentadas con urgencia, de transformaciones de mayor hondura que durante esta pandemia encuentran condiciones excepcionales para consolidarse: automatización de fábricas y oficinas, flexibilidad del tiempo y lugar de trabajo, plataformas que median nuestras interacciones laborales y una profunda crisis del trabajo de cuidados. Todo lo cual no sería posible sin la expansión de empresas tecnológicas y nuevos modos de organizar la producción ocurridos durante las últimas décadas.

El propósito de este artículo es advertir transformaciones seculares en la producción y el trabajo visibilizadas durante la pandemia. Para ello se analizan algunas transformaciones de la industria tecnológica, formas de trabajo que se consolidan durante la crisis sanitaria y diversas resistencias que emergen ante estas nuevas formas de explotación. Finalmente, se releva la importancia de la acción colectiva y sus posibilidades de orientar la fisonomía que el trabajo tendrá en un mundo pospandemia.

\section{EL NACIMIENTO DE UN GIGANTE: LA INDUSTRIA TECNOLÓGICA}

El agotamiento de los Estados de bienestar y el estancamiento de las tasas de ganancia durante los años setenta y ochenta del siglo XX abren cursos para 
transformaciones productivas y condiciones para reformas monetaristas (Ruiz, 2019). La liberalización de los mercados permite un ciclo de crecimiento sostenido por capitales financieros que durante los años noventa encuentra rápidos dividendos en las empresas puntocom que, pese a no ser más que una burbuja bursátil (Brenner, 2003), permiten la renovación tecnológica de diversos sectores productivos ${ }^{2}$. Al mismo tiempo, la mayor desregulación, deslocalización y flexibilidad del trabajo, y el debilitamiento de los sindicatos incrementan la población disponible para emplearse en condiciones cada vez más desprotegidas (Castel, 2015).

Tras la crisis financiera de 2008, las bajas tasas de interés movilizan parte de la inversión privada hacia empresas tecnológicas cuya base de innovación se encuentra en iniciativas estatales o redes de colaboración universitaria (Mazzucato, 2013). Son empresas de muy diversa naturaleza que prestan servicios de alojamiento de datos, soporte computacional, operaciones industriales y comerciales, venta y entrega de productos, transporte o alojamiento, al tiempo que extraen todos los datos posibles de sus usuarios, clientes corporativos o trabajadores que, con diversos grados de conciencia, les entregan derechos para su explotación comercial. No obstante, los datos son materia prima que solo una vez organizada y analizada mediante trabajo y tecnologías adquieren valor para ser ofertada a clientes que requieren de servicios de información, soporte tecnológico, logística y todo tipo de aplicaciones para organizar emprendimientos o trabajos (Srnicek, 2018). Este esquema de subvenciones cruzadas, en que las plataformas de recolección son financiadas por la venta de productos o servicios, generan tendencias monopólicas en la extracción y explotación de datos (Boccardo, 2019), una ampliación constante de su giro de negocios y el establecimiento de cadenas de valor que abarcan desde multinacionales hasta pequeños productores locales en todo el mundo (Thompson \& Smith, 2017).

El gigante tecnológico que mejor expresa este modelo de negocios es, sin duda alguna, Amazon (Galloway, 2017). La empresa fundada por Jeff Bezos, que en 2017 se convirtió en la mayor fortuna individual del mundo, se extiende literalmente desde la A hasta la $\mathrm{Z}^{3}$. Pese a ser mundialmente conocida como una plataforma comercial y de entrega de productos (originalmente, libros), ha desarrollado un complejo industrial integrado por muchas ramas y filiales: servicios de logística global que incluyen talleres, bodegas, flotas de camiones, barcos, aviones y drones para llegar en el menor tiempo posible a todos los rincones del mundo; servicios tecnológicos,

2. Durante ese mismo periodo, el capital financiero especula en ámbitos tan diversos como la emergente industria manufacturera en Asia y la extracción de recursos naturales, en agronegocios y energía, en América Latina y África (Brenner, 2003).

3. El ícono de Amazon contiene una flecha que une la letra A con la Z, lo que demuestra la amplitud con que Jeff Bezos concibe los alcances de su industria. 
de operaciones, almacenamiento de datos y de logística industrial a empresas en distintas ramas productivas (Amazon Web Service); desarrollo de tecnologías como lectores de libro (Kindle), altavoces inteligentes (Echo), asistentes de voz con algún grado de inteligencia artificial (Alexa), servicios de streaming de videos, música, series y películas (incluido Amazon Studio para producciones cinematográficas) que apuntan a registrar y organizar toda nuestra experiencia social; su filial de robótica en que desarrolla soluciones automatizadas para la industria y el comercio; cadenas de supermercados físicos como Whole Food Markets o Amazon Go (primer supermercado en que el pago se realiza sin pasar por caja); y, finalmente, Mechanical Turk, que es una plataforma de crowdsourcing para realizar trabajos simples y de bajo precio unitario que requieren un cierto nivel de inteligencia que una máquina no puede proveer. En suma, emerge un gigante global con capacidad de ofrecer bienes y servicios de todo tipo, reestructurar sectores productivos completos y reorganizar el trabajo, encadenando todo tipo de calificaciones y formas de disciplinamiento (Delfanti, 2019), pero que, al mismo tiempo, constituye un esfuerzo decidido por alterar mediante la explotación de datos la forma de organizar toda nuestra vida social.

Es este modelo el que se ha consolidado durante la pandemia. Hemos visto cómo se ha masificado el uso de plataformas como Zoom, Meet (Google), Team (Microsoft) o WhatsApp (Facebook), que permiten que millones de personas puedan trabajar, estudiar, comprar o pasar tiempo de esparcimiento desde cualquier lugar y en cualquier momento, siempre que cuenten con un "dispositivo inteligente" y una conexión a Internet. También se han expandido o reconvertido plataformas como Uber Eats, Cornershop o Didi para mantener la cadena de suministros y la distribución del comercio minorista funcionando. De un modo menos visible, millones de empresas en diversos rubros productivos aumentaron su dependencia de plataformas de "servicios de nube" y soporte técnico como Microsoft Azure o Amazon Web Service para mantener el negocio funcionando.

¿Qué tiene que ver todo esto con la crisis sanitaria, el trabajo y nuestro futuro? Precisamente, son este tipo de transformaciones las que posibilitan una masificación de plataformas que median todo tipo de relaciones humanas. No es que antes de la pandemia esto no ocurriera, sin embargo, esta forzó a que prácticamente todas nuestras interacciones sean registradas por aplicaciones, lo que ha consolidado su poder en la economía y sociedad. En efecto, su expansión está alterando la organización del trabajo que proporcionan directa e indirectamente, la de sus proveedores, pero también del creciente número de empresas y fuerza de trabajo que dependen de sus productos y servicios. Es decir, potencialmente estamos hablando del conjunto de la población humana interactuando a través de plataformas. Pero a diferencia de los encadenamientos de la industria automotriz del siglo XX, estos 
gigantes tecnológicos apalancados por capital financiero tienen una voraz capacidad de alterar el tiempo y el espacio de trabajo, al punto de imbricarlo con el resto de nuestra experiencia vital. De ahí su relevancia para advertir formas de trabajo futuro.

\section{PANDEMIA: ¿UN LABORATORIO PARA NUEVAS FORMAS DE TRABAJO?}

Los efectos sociales de la pandemia han vuelto a instalar al trabajo en el ojo del huracán. Los gobiernos realizan desesperados esfuerzos por mantener el empleo y los salarios, y entregar todo tipo de fondos con el propósito de evitar un descalabro económico mayor. Sin embargo, el último informe de la Organización Internacional del Trabajo (2020) demostró que estas medidas han resultado insuficientes: durante el primer trimestre del 2020 se perdieron $4,5 \%$ por ciento de las horas trabajadas (lo que equivale a unos 130 millones de empleos a jornada completa), 68 por ciento de la fuerza de trabajo mundial vive en países con medidas de confinamiento social, un 37,5 por ciento estaba empleada en actividades económicas en riesgo de quiebra y alrededor de 1,6 billones de personas ocupadas en la economía informal podrían ver peligrar su fuente de ingresos. En suma, se trata de una crisis del trabajo de proporciones desconocidas que afecta todo tipo de países, ramas productivas y calificaciones laborales, y desborda los alcances de las instituciones de seguridad social.

Para quienes han podido conservar su fuente de empleo, el foco de atención se encuentra en cómo la pandemia intensifica el uso de tecnologías, modifica nuestra forma de trabajar, y en las diversas acciones de resistencia de la fuerza de trabajo.

Trabajadores y trabajadoras de la industria extractiva, manufacturas, construcción o faenas se exponen a diario para mantener la cadena de suministros funcionando. Las exigencias de seguridad y distanciamiento social, y la reducción del trabajo presencial han forzado la inversión en tecnologías para mantener el tranco de la producción: nueva maquinaria y software para informatizar procesos, digitalizar recursos, crear mayor ciberseguridad y sistemas de coordinación en línea con proveedores, servicios de logística, clientes y el trabajo realizado desde los hogares ${ }^{4}$. Son transformaciones que aumentan el encadenamiento con gigantes tecnológicos y posibilitan una menor presencia física y/o una reducción de la fuerza de trabajo permanente. No obstante, cuando las regulaciones laborales son menos estrictas

4. Para una revisión acabada del impacto de la pandemia en las empresas se pueden revisar diversos informes publicados por la consultora Price Waterhouse Coopers (PwC) en https:// www.pwc.com/gx/en/issues/crisis-solutions/covid-19.html 
o el empleo se ubica en la economía informal, la fuerza de trabajo ha tenido que "optar" entre exponerse al contagio o perder su fuente laboral. Este ha sido el caso de cadenas de supermercado o tiendas por departamento que presionan para que su personal de ventas asista pese a los riesgos inminentes de contagio.

Otro elemento sensible durante la crisis sanitaria es el trabajo de logística. Este incluye puertos aéreos y marítimos, carreteras y una red de transporte público y privado encargada de movilizar personas y entregar bienes y servicios en ciudades confinadas. Aquellas empresas que realizan transporte de pasajeros (como aerolíneas, trenes o buses) o cuyas cadenas de suministro dependen de relaciones presenciales se encuentran en riesgo de quiebra inminente. En cambio, aquellas que cuentan con tecnología de compra, venta y distribución virtual y/o logística propia han visto crecer su demanda y empleo. Sin embargo, se registra una heterogénea gama de condiciones laborales que van desde protecciones sociales y rigurosas medidas de seguridad hasta modalidades sin contrato, como ocurre en el caso de ciclistas y motoristas de Uber Eats, Rappi o Glovo, que recorren ciudades vacías entregando compras para contribuir al confinamiento de la población.

La modalidad que ha acaparado mayor atención durante la pandemia es el teletrabajo. El confinamiento obligatorio de la población, que incluye la suspensión de escuelas y todo tipo de servicios de cuidados, ha significado un vaciamiento de las oficinas y que miles de hogares se hayan convertido en improvisados puestos de trabajo conectados mediante computadores, plataformas e Internet con sus empleadores. Una modalidad que no se reduce a las profesiones liberales, sino que se extiende a ocupaciones tan diversas como docencia básica, secundaria y universitaria, tareas de soporte técnico, servicios de contabilidad y administración de oficinas, ventas de productos o servicio de atención al cliente. Son millones de trabajos ejercidos mayormente por mujeres que, producto del confinamiento, se exponen a una mayor carga de trabajo de cuidados y situaciones de violencia intrafamiliar (Deutsche Welle, 2020a). En ese sentido, el teletrabajo no solo altera el modo de ejercer profesiones u oficios, sino que obliga a una reorganización total de los hogares, a asumir mayores costos en tecnología e insumos básicos, y dificulta poner límites a la jornada laboral, lo que agudiza su superposición con el trabajo de cuidados.

Pese a que las situaciones más visibles obedecen a dilemas de contagio y sustento cotidiano, observamos un cambio mucho más profundo que pone a los gigantes tecnológicos en el centro de la producción y a las plataformas como uno de los principales mediadores de las relaciones laborales. La extracción de datos está aumentando las posibilidades de conocer cómo trabajamos y generar aprendizajes para futuras automatizaciones y procesos de descalificación laboral. Se trata de una expansión del espacio y los tiempos de trabajo encadenado con el uso social de 
las plataformas: conversaciones, relaciones de pareja, actividades de esparcimiento, estudios, compras, entre otros. Además, estos cambios tienen consecuencias en la desigual distribución de la carga de cuidados en perjuicio de las mujeres: como se ha visto durante la pandemia, la mayor flexibilidad de jornadas y de espacios de trabajo consolida los estereotipos de género y restringe aún más los espacios de autonomía y el tiempo libre de las mujeres (Alon et al., 2020). En suma, la crisis sanitaria está pavimentando el camino para que tiempo y espacio de trabajo remunerado, de cuidados y de esparcimiento se diluyan bajo la mediación de diversas plataformas controladas por gigantes cuya capacidad de vigilancia se consolida en el tiempo (Zuboff, 2019).

Por dramática que parezca la coyuntura, durante su desarrollo han emergido un sinfín de expresiones de solidaridad que pueden ser base para una nueva fuerza laboral. Los sindicatos han resultado claves para distribuir implementos de seguridad, alcanzar acuerdos que protejan el empleo y los salarios de afiliados u organizar turnos diferenciados para asegurar el distanciamiento social. La acción sindical ha permitido también visibilizar situaciones de abuso e irregularidades laborales. Por ejemplo, en tiendas de supermercados, talleres y bodegas, restaurantes y otro tipo de servicios se han organizado cadenas de información para saber el número de contagiados y así evitar una exposición forzada por los empleadores (Paul, 2020), y se está convocando a huelgas para exigir la realización de test, la entrega de implementos de seguridad y mejoras en los pagos (Medina, 2020). En otros casos, la solidaridad proviene de organizaciones feministas que registran el aumento de la violencia intrafamiliar y exigen medidas de protección a mujeres confinadas (Deutsche Welle, 2020b), mientras que diversas organizaciones territoriales se coordinan para evitar situaciones de hambre extrema (Cisternas, 2020). En suma, pese a la dureza de la pandemia y el temor al desempleo, estas nuevas modalidades de explotación exacerbadas durante la crisis sanitaria configuran redes de solidaridad y resistencias que desbordan los límites espaciales y temporales de fábricas y oficinas.

Una vez finalizada la pandemia, las ocupaciones mediadas por plataformas aumentarán. Para visiones optimistas, es el comienzo de una nueva era de bienestar en que las tecnologías permitirán trabajar menos, producir más y vivir mejor (Brynjolfsson \& McAfee, 2014). No obstante, perspectivas críticas han advertido que la automatización está generando mayor control y descalificación de la fuerza de trabajo (Boccardo, 2020a; Kendra Briken et al., 2017), y de no tomar medidas radicales estaremos ad portas de una nueva era de desigualdades (Gnutti, 2017). Más allá de estas proyecciones, los grandes conglomerados multinacionales se encuentran discutiendo sobre el ahorro en metros cuadrados, la reducción de costos en insumos, una mayor flexibilidad de la jornada y posibilidades de control (Koetsier, 2020). 
En ese sentido, sería un error pensar que en el futuro todo el trabajo se realizará de manera remota o que toda automatización será sinónimo de desempleo. La posibilidad de conectarse en todo espacio y tiempo hará del trabajo una experiencia omnipresente que no se reducirá al confinamiento en el hogar, lo que diluirá una premisa elemental del capitalismo industrial: que el trabajador vende "voluntariamente" su tiempo de trabajo y que el capital proporciona el espacio y los medios de producción. Pero, también, el trabajo remunerado se imbricará de forma mucho más significativa con el trabajo de cuidados realizado por las mujeres. De allí la relevancia de abordar la "crisis de los cuidados" y el potencial transformador que comportan los conflictos asociados a este tipo de desigualdades en el trabajo.

En definitiva, la cuestión no radica en una tecnología específica o en el espacio en que se desempeña un trabajo, sino en el uso concreto que el capitalismo hace de estos para elevar la explotación. Como señala Marx en El capital, la introducción de tecnologías en la producción altera las formas de valorización, explotación y organización del proceso de trabajo. No obstante, esa misma tecnología puede devenir en una poderosa herramienta para generar vínculos de coordinación más profundos y de mayor solidaridad, tal como hemos observado durante la pandemia. En ese sentido, el problema no es de orden técnico, sino eminentemente político.

\section{DILEMAS DEL TRABAJO EN UN MUNDO POSPANDEMIA}

Durante la era neoliberal, la forma de trabajar está cambiando tan radicalmente que un mundo pospandemia requerirá mucho más que el "retorno del Estado", el fortalecimiento de los sindicatos o la recuperación de viejas utopías socialistas.

En el corto plazo, la recesión y la transformación tecnológica provocarán un desempleo exponencial que hay que atender de modo urgente (que la propia OIT cifró en cientos de millones de personas en todo el mundo). No obstante, una vez terminada la crisis sanitaria, uno de los grandes dilemas será cómo transformar un sistema de relaciones laborales, instituciones de seguridad social y sindicatos fuertemente enraizados en formas de trabajo propias del siglo XX. Esto último resulta crucial, ya que durante la pandemia hemos observado que las nuevas formas de producción y de trabajo están desbordando todas las regulaciones estatales conocidas. En esa dirección, urge un nuevo diseño laboral que recupere derechos expropiados por el neoliberalismo, pero sobre todo se avance en una institucionalidad que dé cuenta de las nuevas formas de trabajar, en su más amplio sentido (Boccardo, 2020b).

A pesar de las distopías que avizoran un mundo sin trabajo (Ford, 2015; Frey \& Osborne, 2017), la automatización no es un proceso determinado de antemano. 
Es cierto que la expansión de una nueva fuerza de trabajo subordinada al control de plataformas puede debilitar a los sindicatos anclados en un lugar físico y jornada establecida. Sin embargo, la extensión y velocidad de la descalificación sitúa bajo una experiencia común a trabajadores y trabajadoras con diversas calificaciones que resisten y despliegan nuevas formas de solidaridad que rompen con las viejas jerarquías del prestigio ocupacional. Ahora bien, un nudo gordiano a destrabar para cualquier generalización de intereses en el trabajo y la formación de una fuerza transformadora es enfrentar la división sexual del trabajo en lo doméstico y en el mercado laboral. De lo contrario, trabajar seguirá siendo una experiencia tan desigual para hombres y mujeres, que será prácticamente imposible alcanzar una organización en común. En este sentido, la actual coyuntura puede ser una oportunidad para repensar las formas de acción y organización de quienes vivimos del trabajo, acelerar la crisis de las estructuras más autoritarias y patriarcales de la clase obrera, y dotarnos de principios de seguridad laboral que efectivamente nos protejan y entreguen mayor autonomía.

De momento, resulta difícil prever si el mundo saldrá fortalecido o debilitado después de la pandemia. En buena medida, dependerá de la acción mancomunada de trabajadores y trabajadoras hacer de las nuevas condiciones del trabajo un espacio de solidaridad capaz de forjar instrumentos de organización y lucha que expresen la heterogeneidad existente y permitan alcanzar mayores niveles de libertad y bienestar. De lo que se trata, en definitiva, es de centrar en la acción colectiva las posibilidades de democratizar la producción y el Estado, pero también la propia sociedad. 


\section{REFERENCIAS}

Alon, Titan; Doepke, Matthias; Olmstead-Rumsey, Jane; Tertilt, Michéle. The impact of Covid-19 on gender equality. National Bureau of Economic Research, 2020. Disponible en: https://www.nber.org/papers/w26947.pdf

Amadeo, Pablo. Sopa de Wuhan, pensamiento contemporáneo en tiempos de pandemias. Editorial Aspo (Aislamiento Social Preventivo y Obligatorio), 2020.

Antunes, Ricardo; Mészáros, István. Los sentidos del trabajo: ensayo sobre la afirmación y la negación del trabajo. Buenos Aires: Herramienta Ediciones, 2005.

Boccardo, Giorgio. Can robots produce customer confidence? Contradictions among automation, new mechanisms of control and resistances in the banking labour process. En: Artificial Intelligence, Automation and Work. United Kingdom, Pluto Press, 2020a.

Boccardo, Giorgio. Defender el trabajo es salvar vidas. Radio Universidad de Chile, 2020b [en línea]. <https://radio.uchile.cl/2020/05/01/defender-el-trabajoes-salvar-vidas / $>$ [consulta: 1 de junio de 2020b].

Boccardo, Giorgio. Industria de datos: tendencias seculares, nuevas desigualdades y desafíos para la democracia. Palabra Pública, 2019, 13, pp. 59-63.

Brenner, Robert. La expansión económica y la burbuja bursátil. Barcelona: Ediciones Akal, 2003.

Brynjolfsson, Erik; Mcafee, Andrew. The second machine age: Work, progress, and prosperity in a time of brilliant technologies. New York, WW Norton \& Company, 2014.

Castel, Robert. El ascenso de las incertidumbres: trabajo, protecciones, estatuto del individuo. Buenos Aires: Fondo de Cultura Económica, 2010.

Castel, Robert. La inseguridad social: ¿qué es estar protegido? Buenos Aires, Ediciones Manantial, 2015.

Cisternas, María Luisa. Otra vez las mujeres: las ollas comunes contra la desesperación en tiempos de crisis [en línea]. Radio Universidad de Chile, 2020. <https:// radio.uchile.cl/2020/05/18/otra-vez-las-mujeres-las-ollas-comunes-contrala-desesperacion-en-tiempos-de-crisis/> [consulta: 31 de mayo de 2020].

Delfanti, Alessandro. Machinic dispossession and augmented despotism: Digital work in an Amazon warehouse. New Media \& Society, 2019, pp. 1-17. 
Deutsche Welle. OMS confirma aumento de violencia contra mujeres por cuarentenas [en línea]. Deutsche Welle <https://www.dw.com/es/oms-confirmaaumento-de-violencia-contra-mujeres-por-cuarentenas/a-53366780> [consulta: 1 de junio de 2020a].

Deutsche Welle. Cuarentena por coronavirus dispara violencia contra las mujeres en América Latina [en línea]. Deutsche Welle <https://www.dw.com/ es/cuarentena-por-coronavirus-dispara-violencia-contra-las-mujeres-enam\%C3\%A9rica-latina/a-53261868> [consulta: 1 de junio de 2020b].

Ford, Martin. The rise of the robots: Technology and the threat of mass unemployment. London, OneWorld, 2015.

Frey, Carl; Osborne, Michael. The future of employment: How susceptible are jobs to computerization? Technological forecasting and social change, 2017, vol. 114, pp. 254-280.

Galloway, Scott. The four: the hidden DNA of Amazon, Apple, Facebook and Google. London, Random House, 2017.

Gnutti, Rudy. El mundo sin trabajo: pensando con Zygmunt Bauman. Barcelona, Icaria Editorial, 2017.

ILO Monitor. Covid-19 and the world of work. Third edition. Updated estimates and analysis. ILO, 2020. Disponible en: https://www.ilo.org/wcmsp5/groups/ public/@dgreports/@dcomm/documents/briefingnote/wcms_743146. pdf

Kendra, Briken; Chillas, Shiona; Krzywdzinski, Martin; Marks, Abigail. Labour Process Theory and New Digital Workplace. The new digital workplace: how new technologies revolutionize work. London, Palgrave Macmillan Education, 2017.

Koetsier, John. How A 55,000-Person Enterprise Moved 95\% Of Its Employees To Home Offices. In: 6 Weeks [en línea]. Forbes, 2020. < https:/ /www.forbes. com/sites/johnkoetsier/2020/05/19/how-a-55000-person-enterprisemoved-95-of-its-employees-to-home-offices-in-6-weeks/\#18bd01bc6d98> [consulta: 31 de mayo de 2020].

Mazzucato, Mariana. The entrepreneurial state, debunking private vs. public sector myths in risk and innovation. London, Anthem Press, 2013.

Medina, Daniel A. As Amazon, Walmart, and Others Profit Amid Coronavirus Crisis, Their Essential Workers Plan Unprecedented Strike [en línea]. The Intercept, 2020. <https://theintercept.com/2020/04/28/coronavirus-may1-strike-sickout-amazon-target-whole-foods/> [consulta: 2 de junio de 2020]. 
Paul, Kari. Tracking tool allows Amazon workers to report Covid-19 cases. The Guardian, 2020 <https://www.theguardian.com/world/2020/may/06/ tracking-tool-allows-amazon-workers-to-report-covid-19-cases $>$ [consulta: 31 de mayo de 2020]

Roubini, Nouriel. The Coming Greater Depression of the 2020s [en línea]. Project Syndicate, $2020<$ https://www.project-syndicate.org/commentary/greaterdepression-covid19-headwinds-by-nouriel-roubini-2020-04> [consulta: 31 de mayo de 2020].

Ruiz, Carlos. La política en el neoliberalismo. Experiencias latinoamericanas. Santiago, LOM Ediciones, 2019.

Srnicek, Nick. Capitalismo de plataformas. Buenos Aires, Caja Negra, 2018.

Stiglitz, Joseph. Internationalizing the Crisis [en línea]. Project Syndicate, 2020 <https://www.project-syndicate.org/commentary/covid19-impact-ondeveloping-emerging-economies-by-joseph-e-stiglitz-2020-04> [consulta: 31 de mayo de 2020].

The Editorial Board. Virus lays bare the frailty of the social contract radical reforms are required to forge a society that will work for all [en línea]. Financial Times, $2020<$ https://www.ft.com/content/7eff769a-74dd-11ea-95fefcd274e920ca> [consulta: 31 de mayo de 2020].

Thompson, Paul; Smith, Chris. Working life: renewing labour process analysis. London, Palgrave Macmillan, 2017.

Zuboff, Shoshana. The age of surveillance capitalism: The fight for a human future at the new frontier of power. London, Profile Books, 2019. 